\title{
Analisis Perbandingan Jumlah Pasien Sebelum dan Setelah Pandemi Covid-19 UPT Puskesmas Tahun 2019-2020
}

\section{Comparative Analysis of the Number of Patients Before and After the Covid-19 Pandemic UPT Puskesmas 2019-2020}

\author{
Aflahul Tsaqif \\ Perekam Medis UPT Puskesmas Reban Kabupaten Batang \\ Jl. Apollo No 66 Gang Melati 5 RT.08 RW. 05 Kandang Panjang, Pekalongan Utara \\ E-mail: tsaqifafl@gmail.com
}

\begin{abstract}
Medical records are records of who, what, why when, and how services are provided to patients during the treatment period. This study is intended to compare the number of patient visits before and after the Covid-19 Pandemic. The character of this research is descriptive by describing and explaining the number of patients, and the approach in this research uses a quantitative approach. This study uses primary and secondary data at the UPT Puskesmas. The primary data in this study were researchers directly interviewing patients who had visited before and after the Covid-19 pandemic, while the secondary data was that researchers used data from the Medical Records Unit in the form of patient visits from March - December 2019 and March - December 2020. The results of this study is that there is a decrease in the number of patients as many as 1401 patients. And the factor that affects patient visits is the level of patient confidence in the Covid-19 Pandemic, patients are worried that when they visit the Puskesmas they will be infected with Covid-19.
\end{abstract}

Keyword: Medical Records, Covid-19 Pandemic, UPT Puskesmas

\begin{abstract}
Abstrak
Rekam medis adalah rekaman mengenai siapa, apa, mengapa bilamana, dan bagaimana pelayanan yang diberikan kepada pasien selama masa perawatan. Informasi didalam rekam medis juga memuat jumlah kunjungan pasien. Penelitian ini dimaksud untuk membandingkan jumlah kunjungan pasien sebelum dan setelah adanya Pandemi Covid-19. Metode penelitian ini adalah deskriptif dengan menggambarkan dan menjelaskan berapa jumlah pasien, dan pedekatan dalam penelitian penelitian ini menggunakan pendekatan yang bersifat kuantitatif. Penelitian ini menggunakan data primer dan sekunder di UPT Puskesmas. Data primer dalam penelitian ini adalah peneliti mewawancarai secara langsung pasien yang pernah berkunjungan sebelum dan setelah adanya Pandemi Covid-19 sedangkan data sekundernya adalah peneliti menggunakan data dari Unit Rekam Medis berupa jumlah kunjungan pasien dari bulan Maret - Desember 2019 dan Maret - Desember 2020. Hasil analisis dari penelitian ini adalah terdapat penurunan jumlah pasien sebanyak 1401 pasien. Dan faktor yang mempengaruhi kunjungan pasien adalah tingkat kepercayaan pasien terhadap Pandemi Covid19, pasien merasa khawatir apabila berkunjung ke Puskesmas maka akan tertular Covid-19.
\end{abstract}

Kata kunci : Rekam Medis, Pandemi Covid-19, UPT Puskesmas 


\section{A. Pendahuluan}

Puskesmas dalam perannya sebagai penyedia pelayanan kesehatan dituntut agar dapat memberikan layanan kesehatan secara cepat, akurat dan tepat. Pemanfaatan teknologi informasi sangat dibutuhkan oleh puskesmas sebagai sarana kesehatan primer untuk memudahkan proses pelayanan dan pengelolaan data kesehatan (Rosalina, 2017). Didalam pemanfaatan teknologi Informasi maka perekam medis di puskesmas akan merekam data jumlah pasien dari bagian Pendaftaran.

Rekam Medis sesuai dengan Pasal 46 ayat (1) UU Praktik Kedokteran adalah berkas yang berisikan catatan dan dokumen tentang identitas pasien, pemeriksaan, pengobatan, tindakan dan pelayanan lain yang telah diberikan kepada pasien (Sunny Ummul Firdaus, 2008). Rekam Medis adalah rekaman mengenai siapa, apa, mengapa bilamana, dan bagaimana pelayanan yang diberikan kepada pasien selama masa perawatan, yang memuat pengetahuan mengenai pasien dan pelayanan yang diperoleh serta memuat informasi yang cukup untuk mengidentifikasi pasien, membenarkan diagnosis dan pengobatan serta merekam hasilnya (WHO, 2010). Selama pasien dirawat jalan ataupun rawat inap akan ada pembagian apakah pasien tersebut terklasifikasikan sebagai Pasien BPJS PBI, Non PBI dan Mandiri. BPJS merupakan program pemerintah dalam satu kesatuan Jaminan Kesehatan Nasional (JKN), Badan Penyelenggara Jaminan Sosial (BPJS) adalah badan hokum yang dibentuk untuk menyelenggarakan program jaminan sosial. Jaminan social adalah satu bentuk perlindungan sosial untuk menjamin seluruh rakyat agar dapat memenuhi kebutuhan hidup yang layak (Dewan Perwakilan Rakyat Republik Indonesia, 2011)

Pada 31 Desember 2019, WHO China Country Office melaporkan kasus pneumonia yang tidak diketahui etiologinya di Kota Wuhan, Provinsi Hubei, Cina. Pada tanggal 7 Januari 2020, Cina mengidentifikasi pneumonia yang tidak diketahui etiologinya tersebut sebagai jenis baru coronavirus (coronavirus disease, COVID-19). Pada tanggal 2 Maret 2020, Indonesia melaporkan kasus konfirmasi COVID-19 sebanyak 2 kasus. Sampai dengan tanggal 25 Maret 2020, Indonesia sudah melaporkan 790 kasus konfirmasi COVID19 dari 24 Provinsi yaitu: Bali, Banten, DIY, DKI Jakarta, Jambi, Jawa Barat, Jawa Tengah, Jawa Timur, Kalimantan Barat, Kalimantan Timur, Kalimantan Tengah, Kalimantan Selatan, Kep. Riau, Nusa Tenggara Barat, Sumatera Selatan, Sumatera Utara, Sulawesi Utara, Sulawesi Tenggara, Sulawesi Selatan, Lampung, Riau, Maluku Utara, Maluku dan Papua (Direktorat Jenderal Pencegahan dan Pengendalian Penyakit, 2020).

Penelitian yang dilakukan peneliti terkait dengan perbandingan jumlah pasien yang berkunjung ke UPT Puskesmas akan berfokus pada perbandingan jumlah pasien sebelum adanya Pandemi Covid-19 dan Setelah Pandemi Covid-19. Berdasarkan studi kasus awal pada 10 bulan antara Maret, April, Mei, Juni, Juli, Agustus, September, Oktober, November, Desember 2019 dan Maret, April, Mei, Juni, Juli, Agustus, September, Oktober, November, Desember 2020 ada selisih jumlah pasien 
yang berkunjung di UPT Puskesmas sebanyak 1401 pasien. Oleh karena itu, peneliti tertarik untuk memberikan pembahasan terkait permasalahan tersebut.

\section{B. Metode Penelitian}

Pendekatan yang digunakan adalah bersifat kuantitatif yang memiliki karakteristik bersifat deskriptif. Data yang yang dikumpulkan berupa data primer yaitu langsung dari sumbernya berupa wawancara terhadap pasien, dalam penelitian ini peneliti mewawancarai 20 pasien dan data sekunder yaitu data tidak langsung dari unit rekam medis, peneliti menjadi bagian dari instrumen pokok analisisnya, kedua data berupa kata-kata dalam kalimat atau gambar yang mempunyai arti (HB Sutopo, 2006). Pendekatan deskriptif yaitu menggambarkan tentang perbandingan hasil analisis Jumlah Kunjungan pasien sebelum dan Setelah Pandemi Covid-19, serta bersifat analitik yaitu menganalisa perbandingan jumlah kunjungan pasien sebelum dan Setelah Pandemi Covid-19. Penelitian ini dilakukan dari 12 Februari 2021- 26 Februari 2021 di Unit Rekam Medis UPT Puskesmas.

Populasi dalam penelitian ini adalah seluruh jumlah kunjungan pasien 10 bulan sebelum Pandemi Covid-19 dan 10 bulan Setelah Pandemi Covid-19. Pengambilan sampel dalam penelitian ini secara purposive didasarkan pada suatu pertimbangan tertentu yang dibuat oleh peneliti sendiri, berdasarkan citi atau sifat populasi yang sudah diketahui sebelumnya (Soekidjo Notoatmodjo). Dengan menggunakan purposive sampling maka populasi yang ada akan dijadikan sampel sesuai dengan keinginan peneliti.

\section{Hasil dan Pembahasan}

Tabel 1

Kunjungan Pasien Bulan Maret - Desember 2019 Sebelum Pandemi Covid-19 Sumber Data : Unit Rekam Medis UPT Puskesmas

\begin{tabular}{|c|c|c|c|c|c|c|c|}
\hline \multirow{2}{*}{ Bulan } & \multicolumn{2}{|c|}{ PBI } & \multicolumn{2}{|c|}{$\begin{array}{c}\text { NON } \\
\text { PBI }\end{array}$} & \multicolumn{2}{|c|}{$\begin{array}{c}\text { MAN } \\
\text { DIRI }\end{array}$} & \multirow{2}{*}{$\begin{array}{l}\text { Jum } \\
\text { lah }\end{array}$} \\
\hline & $\mathrm{L}$ & $\mathrm{P}$ & $\mathrm{L}$ & $\mathrm{P}$ & $\mathrm{L}$ & $\mathrm{P}$ & \\
\hline MARET & 200 & 487 & 48 & 112 & 207 & 288 & 1342 \\
\hline APRIL & 150 & 392 & 60 & 60 & 191 & 262 & 1115 \\
\hline MEI & 148 & 389 & 43 & 72 & 198 & 240 & 1090 \\
\hline JUNI & 177 & 290 & 41 & 58 & 211 & 277 & 1054 \\
\hline JULI & 198 & 281 & 66 & 70 & 198 & 281 & 1094 \\
\hline AGUSTUS & 191 & 364 & 49 & 92 & 212 & 278 & 1186 \\
\hline SEPTEMBER & 165 & 360 & 58 & 73 & 214 & 306 & 1176 \\
\hline OKTOBER & 254 & 435 & 67 & 80 & 190 & 280 & 1306 \\
\hline NOVEMBER & 236 & 436 & 44 & 83 & 161 & 252 & 1212 \\
\hline DESEMBER & 218 & 444 & 62 & 84 & 179 & 233 & 1220 \\
\hline
\end{tabular}


Tabel 2

Kunjungan Pasien Bulan Maret - Desember 2020 Setelah Pandemi Covid-19 Sumber Data : Data Sekunder Unit Rekam Medis UPT Puskesmas

\begin{tabular}{|c|c|c|c|c|c|c|c|}
\hline \multirow[t]{2}{*}{ Bulan } & \multicolumn{2}{|c|}{ PBI } & \multicolumn{2}{|c|}{$\begin{array}{c}\text { NON } \\
\text { PBI }\end{array}$} & \multicolumn{2}{|c|}{$\begin{array}{c}\text { MAN } \\
\text { DIRI }\end{array}$} & \multirow{2}{*}{$\begin{array}{l}\text { Jum } \\
\text { lah }\end{array}$} \\
\hline & $\mathrm{L}$ & $\mathrm{P}$ & $\mathrm{L}$ & $\mathrm{P}$ & $\mathrm{L}$ & $\mathrm{P}$ & \\
\hline MARET & 289 & 579 & 81 & 105 & 252 & 264 & 1570 \\
\hline APRIL & 159 & 258 & 62 & 74 & 108 & 145 & 806 \\
\hline MEI & 112 & 151 & 29 & 43 & 147 & 113 & 595 \\
\hline JUNI & 175 & 347 & 40 & 63 & 609 & 500 & 1734 \\
\hline JULI & 198 & 372 & 60 & 78 & 291 & 270 & 1269 \\
\hline AGUSTUS & 190 & 306 & 41 & 62 & 181 & 213 & 993 \\
\hline SEPTEMBER & 196 & 449 & 57 & 65 & 176 & 227 & 1170 \\
\hline OKTOBER & 121 & 276 & 39 & 71 & 93 & 140 & 740 \\
\hline NOVEMBER & 135 & 324 & 35 & 49 & 104 & 154 & 801 \\
\hline DESEMBER & 164 & 239 & 38 & 45 & 104 & 126 & 716 \\
\hline
\end{tabular}

Pengamatan Kunjungan pasien Bulan Maret - Desember 2019 dan 2020 menggunakan metode analisa Kuantitatif dengan dikategorikan menjadi dua, yaitu Tinggi dan Rendah. Dikategorikan tinggi apabila kunjungan pasien antara bulan yang sama ditahun yang berbeda lebih tinggi. Sedangkan dikategorikan rendah apabila kunjungan pasien antara bulan yang sama ditahun yang berbeda lebih rendah.

Tabel 3

Perbandingan Kunjungan Pasien Bulan Maret - Desember 2020 Sebelum Pandemi Covid-19 Sumber Data : Data Sekunder Unit Rekam Medis UPT Puskesmas

\begin{tabular}{|c|c|c|c|c|c|}
\hline \multirow[t]{2}{*}{ No } & \multicolumn{2}{|c|}{ Tahun 2019} & \multicolumn{2}{|c|}{ Tahun 2020} & \multirow[t]{2}{*}{ Keterangan } \\
\hline & Bulan & $\begin{array}{l}\text { Jum } \\
\text { lah }\end{array}$ & Bulan & $\begin{array}{l}\text { Jum } \\
\text { lah }\end{array}$ & \\
\hline 1 & MARET & 1342 & MARET & 1570 & Maret 2020 lebih tinggi \\
\hline 2 & APRIL & 1115 & APRIL & 806 & April 2019 lebih tinggi \\
\hline 3 & MEI & 1090 & MEI & 595 & Mei 2019 lebih tinggi \\
\hline 4 & JUNI & 1054 & JUNI & 1734 & Juni 2020 lebih tinggi \\
\hline 5 & JULI & 1094 & JULI & 1269 & Juli 2020 lebih tinggi \\
\hline 6 & AGUSTUS & 1186 & AGUSTUS & 993 & Agustus 2019 lebih tinggi \\
\hline 7 & SEPTEMBER & 1176 & SEPTEMBER & 1170 & September 2019 lebih tinggi \\
\hline 8 & OKTOBER & 1306 & OKTOBER & 740 & Oktober 2019 lebih tinggi \\
\hline 9 & NOVEMBER & 1212 & NOVEMBER & 801 & November 2019 lebih tinggi \\
\hline 10 & DESEMBER & 1220 & DESEMBER & 716 & Desember 2019 lebih tinggi \\
\hline
\end{tabular}

Tabel 3 diatas menggambarkan bahwa dari 10 bulan ada 7 bulan ditahun 2019 sebelum adanya pandemi Covid-19 lebih banyak kunjungan pasien di UPT Puskesmas dan ada 3 bulan ditahun 2020 Setelah adanya pandemic Covid-19 lebih sedikit kunjungan pasien di UPT Puskesmas. 
Tabel 4

Kunjungan Pasien Bulan Maret - Desember 2019 Sebelum Pandemi Covid-19

Berdasarkan Jenis Kelamin

Sumber Data : Data Sekunder Unit Rekam Medis UPT Puskesmas

\begin{tabular}{|c|c|c|c|}
\hline \multirow[t]{2}{*}{ No } & \multirow[t]{2}{*}{ Bulan } & \multicolumn{2}{|c|}{$\begin{array}{c}\text { Jenis } \\
\text { Kelamin }\end{array}$} \\
\hline & & $\mathrm{L}$ & $\mathrm{P}$ \\
\hline 1 & MARET & 455 & 887 \\
\hline 2 & APRIL & 401 & 714 \\
\hline 3 & MEI & 389 & 701 \\
\hline 4 & JUNI & 429 & 625 \\
\hline 5 & JULI & 462 & 632 \\
\hline 6 & AGUSTUS & 452 & 734 \\
\hline 7 & SEPTEMBER & 437 & 739 \\
\hline 8 & OKTOBER & 511 & 795 \\
\hline 9 & NOVEMBER & 441 & 771 \\
\hline 10 & DESEMBER & 459 & 761 \\
\hline & Jumlah & 4436 & 7359 \\
\hline
\end{tabular}

Tabel 4 menggambarkan bahwa Jenis Kelamin paling banyak berkunjung sebelum Pandemi Covid-19 adalah Perempuan sebanyak 7359 pasien. Dengan jumlah laki laki sebanyak 4436 pasien dan jumlah perempuan sebanyak 7359 pasien.

Tabel 5

Kunjungan Pasien Bulan Maret - Desember 2020 Setelah Pandemi Covid-19

Berdasarkan Jenis Kelamin

Sumber Data : Data Sekunder Unit Rekam Medis UPT Puskesmas

\begin{tabular}{llcc}
\hline No & \multirow{2}{*}{ Bulan } & \multicolumn{2}{c}{ Jenis } \\
& & Kelamin \\
\cline { 3 - 4 } & & L & P \\
\hline 1 & MARET & 622 & 948 \\
\hline 2 & APRIL & 329 & 477 \\
\hline 3 & MEI & 288 & 307 \\
\hline 4 & JUNI & 824 & 910 \\
\hline 5 & JULI & 549 & 720 \\
\hline 6 & AGUSTUS & 412 & 581 \\
\hline 7 & SEPTEMBER & 429 & 741 \\
\hline 8 & OKTOBER & 253 & 487 \\
\hline 9 & NOVEMBER & 274 & 527 \\
\hline 10 & DESEMBER & 306 & 410 \\
\hline Jumlah & 4286 & 6108 \\
\hline
\end{tabular}

Tabel 5 menggambarkan bahwa Jenis Kelamin paling banyak berkunjung Setelah Pandemi Covid-19 adalah Perempuan sebanyak 6108 pasien. Dengan jumlah laki laki sebanyak 4286 pasien dan jumlah perempuan sebanyak 6108 pasien. 
Tabel 6

Kunjungan Pasien Bulan Maret - Desember 2019 Sebelum Pandemi Covid-19

Berdasarkan Jenis Pembayaran Kunjungan Pasien

Sumber Data : Data Sekunder Unit Rekam Medis UPT Puskesmas

\begin{tabular}{|c|c|c|c|c|}
\hline No & Bulan & PBI & $\begin{array}{l}\text { NON } \\
\text { PBI }\end{array}$ & $\begin{array}{l}\text { MAN } \\
\text { DIRI }\end{array}$ \\
\hline 1 & MARET & 687 & 160 & 495 \\
\hline 2 & APRIL & 542 & 120 & 453 \\
\hline 3 & MEI & 537 & 115 & 438 \\
\hline 4 & JUNI & 467 & 99 & 488 \\
\hline 5 & JULI & 479 & 136 & 479 \\
\hline 6 & AGUSTUS & 555 & 141 & 490 \\
\hline 7 & SEPTEMBER & 525 & 131 & 520 \\
\hline 8 & OKTOBER & 689 & 147 & 470 \\
\hline 9 & NOVEMBER & 672 & 127 & 413 \\
\hline 10 & DESEMBER & 662 & 146 & 412 \\
\hline \multicolumn{2}{|c|}{ Jumlah } & 5815 & 1322 & 4658 \\
\hline
\end{tabular}

Tabel 6 menggambarkan bahwa kunjungan pasien Sebelum Pandemi Covid-19 berdasarkan Jenis Pembayaran Kunjungan Pasien PBI paling banyak pada Bulan Oktober berjumlah 689 pasien, Non PBI paling banyak pada Bulan Maret berjumlah 160 pasien, Mandiri paling banyak pada Bulan September berjumlah 520 pasien. Dengan jumlah pasien PBI sebanyak 5815 pasien, NON PBI sebanyak 1322 pasien, Mandiri sebanyak 4658 pasien.

Tabel 7

Kunjungan Pasien Bulan Maret - Desember 2020 Setelah Pandemi Covid-19

Berdasarkan Jenis Pembayaran Kunjungan Pasien

Sumber Data : Data Sekunder Unit Rekam Medis UPT Puskesmas

\begin{tabular}{|c|c|c|c|c|}
\hline No & Bulan & PBI & $\begin{array}{c}\text { NON } \\
\text { PBI }\end{array}$ & $\begin{array}{l}\text { MAN } \\
\text { DIRI }\end{array}$ \\
\hline 1 & MARET & 868 & 186 & 516 \\
\hline 2 & APRIL & 417 & 136 & 253 \\
\hline 3 & MEI & 263 & 72 & 260 \\
\hline 4 & JUNI & 522 & 103 & 1109 \\
\hline 5 & JULI & 570 & 138 & 561 \\
\hline 6 & AGUSTUS & 496 & 103 & 394 \\
\hline 7 & SEPTEMBER & 645 & 122 & 403 \\
\hline 8 & OKTOBER & 397 & 110 & 233 \\
\hline 9 & NOVEMBER & 459 & 84 & 258 \\
\hline 10 & DESEMBER & 403 & 83 & 230 \\
\hline \multicolumn{2}{|c|}{ Jumlah } & 5040 & 1137 & 4217 \\
\hline
\end{tabular}

Tabel 7 menggambarkan bahwa kunjungan pasien Setelah Pandemi Covid-19 berdasarkan Jenis Pembayaran Kunjungan Pasien PBI paling banyak pada Bulan Maret berjumlah 868 pasien, Non PBI paling banyak pada Bulan Maret berjumlah 186 pasien, 
Mandiri paling banyak pada Bulan Juni berjumlah 1109 pasien. Dengan jumlah pasien PBI sebanyak 5040 pasien, NON PBI sebanyak 1137 pasien, Mandiri sebanyak 4217 pasien.

Tabel 8

Selisih antara Kunjungan Pasien Bulan Maret - Desember 2019 dan 2010

Sebelum dan Setelah Pandemi Covid-19

Sumber Data : Data Sekunder Unit Rekam Medis UPT Puskesmas

\begin{tabular}{lll}
\hline Kunjungan & Kunjungan & Selisih \\
Maret - Desember 2019 & Maret - Desember 2020
\end{tabular}

$11795 \quad 10394 \quad 1401$

Tabel 8 menggambarkan selisih antara kunjungan pasien Bulan Maret - Desember 2019 dan 2020 Sebelum dan Setelah pandemi berjumlah 1401 pasien. Oleh karena itu terdapat sebuah penurunan jumlah pasien sebelum dan setelah Pandemi Covid-19.

Tabel 9

Rekap Penilaian Kunjungan Pasien Pasien

Sebelum dan Setelah Pandemi Covid-19

Sumber Data : Data Primer Wawancara Pasien

\begin{tabular}{|c|c|c|c|c|c|}
\hline \multirow[b]{2}{*}{ No } & \multirow{2}{*}{$\begin{array}{c}\text { Identitas } \\
\text { Pasien }\end{array}$} & \multicolumn{2}{|c|}{$\begin{array}{l}\text { Percaya } \\
\text { Covid-19 }\end{array}$} & \multicolumn{2}{|c|}{$\begin{array}{c}\text { Takut / } \\
\text { khawatir } \\
\text { Berkunjung }\end{array}$} \\
\hline & & Ya & Tidak & Ya & Tidak \\
\hline 1 & Mr. X & $\sqrt{ }$ & & & $\sqrt{ }$ \\
\hline 2 & Mrs. X & $\sqrt{ }$ & & $\sqrt{ }$ & \\
\hline 3 & Mr. X & & $\sqrt{ }$ & & $\sqrt{ }$ \\
\hline 4 & Mr. X & $\sqrt{ }$ & & $\sqrt{ }$ & \\
\hline 5 & Mr. X & $\sqrt{ }$ & & $\sqrt{ }$ & \\
\hline 6 & Mrs. X & $\sqrt{ }$ & & $\sqrt{ }$ & \\
\hline 7 & Mr. X & $\sqrt{ }$ & & $\sqrt{ }$ & \\
\hline 8 & Mrs. X & $\sqrt{ }$ & & $\sqrt{ }$ & \\
\hline 9 & Mr. X & $\sqrt{ }$ & & $\sqrt{ }$ & \\
\hline 10 & Mr. X & & $\sqrt{ }$ & & $\sqrt{ }$ \\
\hline 11 & Mrs. X & $\sqrt{ }$ & & $\sqrt{ }$ & \\
\hline 12 & Mrs. X & & $\sqrt{ }$ & $\sqrt{ }$ & \\
\hline 13 & Mrs. X & $\sqrt{ }$ & & $\sqrt{ }$ & \\
\hline 14 & Mrs. X & & $\sqrt{ }$ & & $\sqrt{ }$ \\
\hline 15 & Mr. X & $\sqrt{ }$ & & $\sqrt{ }$ & \\
\hline 16 & Mr. X & $\sqrt{ }$ & & $\sqrt{ }$ & \\
\hline 17 & Mrs. X & & $\sqrt{ }$ & & $\sqrt{ }$ \\
\hline 18 & Mrs. X & & $\sqrt{ }$ & $\sqrt{ }$ & \\
\hline 19 & Mr. X & $\sqrt{ }$ & & $\sqrt{ }$ & \\
\hline 20 & Mrs. X & $\sqrt{ }$ & & $\sqrt{ }$ & \\
\hline
\end{tabular}

Tabel 9 menggambarkan bahwa dari 20 sampel pasien yang percaya adanya Pandemi Covid-19 berjumlah 14 pasien, tidak percaya adanya Pandemi Covid-19 berjumlah 6 pasien sedangkan pasien yang takut atau khawatir berkunjung berjumlah 15 pasien, tidak takut atau khawatir berkunjung berjumlah 5 orang. Oleh karena itu, lebih banyak pasien yang percaya adanya Pandemi Covid-19 dan akut atau khawatir

Pada dasarnya analisa kuantitatif dari jumlah kunjungan pasien UPT Puskesmas memiliki tujuan untuk mengukur tingkat kunjungan pasien bahwa Pandemi Covid-19 ini menggambarkan penurunan jumlah pasien. Peneliti telah melakukan wawancara terhadap pasien yang pernah berkunjung sebelum dan Setelah Pandemi Covid-19. Dan faktor yang mempengaruhinya adalah tingkat kepercayaan terkait adanya virus Covid19, Pasien merasa khawatir apabila berkunjung ke Puskesmas maka akan tertular Covid-19. Oleh karena itu, FKTP harus memberikan edukasi terhadap pasien bagaimana penerapan protokol dan 
dampak dari pandemi Covid-19 agar pasien tidak sungkan untuk berkunjung ke FKTP kembali. Perlu upaya yang sinergis dalam menumbuhkan rasa kepercayaan terhadap pasien diwilayah kerja. Salah satu cara adalah dengan menggerakkan bidan desa dan promosi kesehatan yang terkait.

Tidak semua FKTP di Indonesia mengalami tingkat penurunan kunjungan pasien. Peneliti hanya menggambarkan tentang kondisi yang terjadi di UPT Puskesmas.

\section{Kesimpulan dan Saran}

Hasil analisa Kuantitatif
menunjukan bahwa Kunjungan Pasien Bulan Maret - Desember 2020 Setelah Pandemi Covid-19 berjumlah 10394 dan Kunjungan Pasien Bulan Maret Desember 2019 Sebelum Pandemi Covid19 berjumlah 11795, artinya mengalami penurunan dengan jumlah 1401 pasien. Oleh karena itu, Puskesmas sebagai FKTP harus berperan penting dalam penanganan Covid-19 agar memberikan rasa aman, nyaman dan percaya akan protokol kesehatan yang diterapkan. Puskesmas juga harus membangun dan memperkuat jejaring dalam upaya mengendalikan penyebaran infeksi Covid19 termasuk pemberdayaan masyarakat.

\section{E. Daftar Pustaka}

1. Rosalina. (2017). Pengujian Kepuasan Sistem Informasi Menggunakan End User Computing Satisfaction. Studi Kasus Sistem Informasi Akademik. Jakarta. UIN Syarif Hidayatullah,

2. Firdaus, Sunny Ummul. (2008) Rekam Medik dalam Sorotan Hukum dan Etik. Surakarta. Lembaga Pengembangan Pendidikan UNS dan UPT Penerbitan dan Percetkan UNS..

3. WHO. (2010). International Statistical Classification of Diseases and Related Health Problem, Ten Revision, Volume 2 Instruction Manua. Geneva : WHO.

4. Dewan Perwakilan Rakyat Republik Indonesia. (2011). Undang-Undang RI No. 24 Tahun 2011 Tentang Badan Penyelenggara Jaminan Sosial. Jakarta. Kementerian Kesehatan RI .

5. Direktorat Jenderal Pencegahan dan Pengendalian Penyakit (P2P). (2020). Pedoman Pencegahan Dan Pengendalian Coronavirus Disesase (Covid-19). Jakarta.

6. Sutopo, HB. (2006). Metode Penelitian Kualitatif. Surakarta. UNS.Press.

7. Notoatmodjo, Soekidjo. (2010). Metodologi Penelitian Kesehatan. Jakarta. Rineka Cipta. 